\title{
Cuidado parental em Leptodactylus natalensis (Amphibia, Anura, Leptodactylidae)
}

\author{
Ednilza Maranhão dos Santos ${ }^{1} \&$ Fabiana Oliveira de Amorim²
}

1. Pós-graduação em Psicobiologia, Departamento de Fisiologia, Universidade Federal do Rio Grande do Norte, 59078-970 Natal, RN. (ednilzamaranhao@yahoo.com.br)

2. Laboratório de Ecofisiologia e Comportamento Animal, Departamento de Morfologia e Fisiologia Animal, Universidade Federal Rural de Pernambuco, 52171-900 Recife, PE. (fabyamorim@yahoo.com.br)

\begin{abstract}
Parental care behaviour in Leptodactylus natalensis (Amphibia, Anura, Leptodactylidae). The present paper reports one more species of the family Leptodactylidae presenting parental care behaviour, Leptodactylus natalensis Lutz, 1930, in which females were observed attending eggs and schools of tadpoles in two temporary ponds in the Atlantic forest of the State of Pernambuco, Brazil.
\end{abstract}

KEYWORDS. Parental care, behaviour, Leptodactylus natalensis, Atlantic forest, Brazil.

RESUMO. O presente trabalho registra mais uma espécie pertencente à família Leptodactylidae apresentando cuidado parental, Leptodactylus natalensis Lutz, 1930. Fêmeas foram observadas em assistência a ovos e cardumes de girinos em duas poças temporárias na mata Atlântica do Estado de Pernambuco, Brasil.

PALAVRAS-CHAVE. Cuidado parental, comportamento, Leptodactylus natalensis, Mata Atlântica, Brasil.

O cuidado parental é constituído por um repertório de comportamentos exibidos pelos pais para com sua prole com o objetivo de assegurar a sobrevivência de seus descendentes. Todavia, o custo com o cuidado parental pode reduzir a capacidade dos pais em investir em outras proles (Trivers, 1972). Em anuros, o cuidado parental pode ser facultativo (MARTINs et al., 1998), maternal, paternal ou biparental (Duellman \& TRueB, 1986; BICKFORD, 2004). Apenas 6\% dos anuros, distribuídos em 17 famílias, apresentam o comportamento de cuidado à prole, nas fases de ovos e larvas (CRUMP, 1996). Relatos de cuidado com a desova e/ou com girinos aquáticos (e.g., Downie, 1996), principalmente com espécies brasileiras (e.g., MARTINS, 2001), são raros.

Entre as famílias que apresentam cuidado parental, Leptodactylidae é a mais diversificada e possui ampla distribuição nas Américas Central e do Sul. Nessa família, o gênero Leptodactylus tem como característica a deposição de ovos em massa de espuma flutuante na lâmina d'água ou em câmaras escavadas no solo (Duellman \& Trueb, 1986; Prado et al., 2002).

Leptodactylus natalensis Lutz, 1930 tem sua ocorrência restrita ao Brasil, tendo sido registrado pela primeira vez na localidade de Rio Baldo, município de Natal, Estado do Rio Grande do Norte, ocorrendo nas localidades litorâneas do Nordeste até o Rio de Janeiro (HEYER, 1994). OliveIRA \& LírIo-JR. (2000) forneceram uma breve descrição do girino desta espécie e Heyer \& Carvalho (2000) descreveram dois tipos de canto. De um modo geral, dados sobre a biologia da espécie em apreço são incipientes. O presente trabalho tem como objetivo relatar o comportamento de cuidado parental em Leptodactylus natalensis em duas áreas de Mata Atlântica no Estado de Pernambuco.

\section{MATERIAL E MÉTODOS}

Foram feitas observações mensais sobre o comportamento de Leptodactylus natalensis entre setembro de 2002 e novembro de 2003 , em duas poças temporárias localizadas em borda de mata de duas localidades do Estado de Pernambuco, Brasil: Estação Ecológica do Tapacurá (EET), localizada no município de São Lourenço da Mata $\left(8^{\circ} 02^{\prime} \mathrm{S}, 35^{\circ} 11^{\prime} \mathrm{W}\right.$ ) (Poça A) e Refúgio Ecológico Charles Darwin (RECD), localizado no município de Igarassu $\left(7^{\circ} 49^{\prime} \mathrm{S}, 34^{\circ} 56^{\prime} \mathrm{W}\right)$ (Poça B). Os animais foram capturados manualmente, medidos com paquímetro (CRA, comprimento rostro-anal), pesados com dinamômetro portátil (Pesola) e marcados através da amputação de falanges (MARTOF, 1953) e colocação de cinto inguinal (EMLEN, 1968). Os indivíduos marcados foram soltos posteriormente nos seus respectivos locais de coleta. Foram utilizados como métodos amostrais a varredura e o animal focal (MARTIN \& BATESON, 1986), no qual o foco era a fêmea, em janelas amostrais de 20 minutos ao longo de um turno de observação de seis horas consecutivas. Foram realizados quatro turnos mensais para cada área, cada um com seis horas diárias consecutivas e em horários complementares, de modo a cobrir as 24 horas do dia. Durante a noite, os animais foram observados com auxílio de uma lanterna com filtro vermelho. Estacas e pegadores amarelos foram utilizados para marcar os locais onde as fêmeas eram encontradas. Foram registrados dados quanto ao tipo de comportamento, localização e o deslocamento da fêmea e suas larvas. Algumas larvas dos cardumes observados foram coletadas para identificação dos estágios de desenvolvimento, utilizando a tabela de GosNer (1960). Todos os dados foram registrados em fichas e caderneta de campo. 


\section{RESULTADOS}

Foram capturadas 65 fêmeas, sendo possível observar cuidado parental em 39 delas. Observamos o cuidado à prole em 12 desovas e 27 cardumes de girinos (Tab. I). Apenas um macho foi registrado próximo às larvas durante seis horas em 24 de novembro de 2002. Durante nossas observações, foram registrados machos de $L$. natalensis construindo bacias $(n=6)$, que serviam como sítio de vocalização e posteriormente sítio de ovipostura.

Inicialmente, foram registrados três tipos de comportamento relacionados ao cuidado parental: assistência, bombeamento (exibidos por fêmeas em atenção às desovas e/ou larvas) e comportamento etepimelético (exibido pelas larvas como resposta à assistência dispensada pelas fêmeas; ver GALLARDO, 1964 ou VAZ-FERREIRA \& GERHAL, 1975). A assistência consistiu na permanência da fêmea junto a desovas e/ou larvas, sugerindo representar uma vigilância contra predadores, uma vez que, durante esta permanência, a fêmea ficava atenta a qualquer movimento e defendia o cardume através de exibições agonísticas como arquear o corpo ou deslocar-se para outro ponto da poça (esse deslocamento variou de 0,01 a $1,00 \mathrm{~m}$ ); quando a assistência era com a desova, as fêmeas podiam se posicionar ao lado, em frente ou embaixo do ninho de espuma. O comportamento de bombeamento caracterizou-se por uma série de movimentos (que variou de 1-21), lentos ou rápidos, de erguer e abaixar a parte posterior do corpo, agitando a superfície da água e produzindo ondulações. $\mathrm{O}$ bombeamento era seguido ou não de deslocamento, que variava de curto a longo $(0,05$ a $0,70 \mathrm{~m}$ ). Após esse comportamento, o cardume seguia a fêmea movendo-se em pequenos aglomerados, geralmente formando dois ou três cardumes menores, até chegarem todos próximos ou junto à fêmea. Na maioria das vezes $(n=116)$, as larvas faziam contato corporal com a fêmea, raspando com a boca ou esfregando suas partes ventrais ou laterais, em movimentos bastante rápidos (comportamento etepimelético, ver Gallardo, 1964). Após esse comportamento, ocorria mais um deslocamento da fêmea e, consequientemente, outro deslocamento das larvas até ela. Observamos que as fêmeas deslocavam-se menos e ficavam mais próximas, ou em contato com os cardumes, quando estes estavam no estágio inicial de desenvolvimento (23-30) do que no estágio intermediário (31-40). No estágio final (41-46) não foi observada a fêmea junto ou próximo ao cardume (Tab. II).

Em novembro de 2002, registramos um ninho em uma bacia coberto por folhedo e uma fêmea (F9) em cuidado parental, ambos distantes da Poça A (cerca de $1,15 \mathrm{~m}$ ), devido à diminuição do nível da água. Durante o turno noturno (das 18 à $00 \mathrm{~h}$ ), observamos que a fêmea em assistência ao ninho, construía um túnel sob o folhedo em solo úmido, ligando o ninho até a lâmina d'água mais próxima (uma poça pequena, distante $0,43 \mathrm{~m}$ ). No turno da manhã do dia seguinte (das 5 às $11 \mathrm{~h}$ ), encontramos a F9 com o cardume na borda da poça central (poça A). Também constatamos que havia outro túnel de $0,68 \mathrm{~m}$, que ligava a poça pequena à poça central e que algumas larvas deslocavam-se por esse túnel até chegarem próximo à fêmea. Comportamento similar foi observado para uma outra fêmea (F15), na mesma poça (A) em maio de 2003

Os eventos $(n=1.032)$ registrados com as fêmeas e suas proles ocorreram tanto no período diurno quanto no noturno. Na maioria das vezes $(n=612)$, os eventos aconteciam quando a fêmea era observada durante o dia, escondida entre a vegetação emergente (Poaceae, Cyperaceae, Curcubitaceae, Acanthaceae) ou parcialmente submersa entre a vegetação flutuante (Laminaceae e Araceae) ou folhedo (folhas secas), sempre na borda da poça ou dentro d'água (profundidade de $0,02$ a $0,15 \mathrm{~m})$. Ocorreram poucos registros $(n=36) \mathrm{de}$ fêmeas fora d'água realizando cuidado parental; nesses, as fêmeas foram observadas no solo ou sobre o folhedo, próximas ou junto ao ninho ou afastadas das larvas quando elas já estavam em estágio intermediário (31-40, Gosner, 1960) (cardume observado na borda da poça profundidade de $0,03 \mathrm{~m}$ ).

Além dos três principais comportamentos (assistência, bombeamento e comportamento etepimelético), foram registrados para L. natalensis mais seis: (1) arquear o corpo: levantar os membros anteriores e posteriores (observado quando invertebrados, aranhas e/ou insetos, se aproximavam do cardume ou da desova ou ainda, quando folhas secas caíam); (2) esconder-se: geralmente embaixo das folhas secas, plantas aquáticas ou entre as plantas emergentes (nesse evento a fêmea era seguida pelas larvas); (3) vocalizar: emissão de sons semelhantes a gemidos, que ocorria quando as larvas se afastavam ou se aproximavam da fêmea e/ou começavam a raspar a sua pele com a boca; (4) deslocar-se: caminhando ou pulando na água ou da água para o solo; (5) mergulhar: pulos na água; geralmente após uma seção de bombeamento; (6) construção de canais: as fêmeas construíam túneis sob o folhedo em solo úmido, através de movimentos do focinho, corpo e membros posteriores ligando o ninho à lâmina d'água mais próxima.

Tabela I. Parâmetros das fêmeas de Leptodactylus natalensis observadas entre setembro de 2002 e setembro de 2003, na Estação Ecológica do Tapacurá (EET) e Refúgio Ecológico Charles Darwin (RECD). (* média \pm desvio padrão).

\begin{tabular}{ccccccc}
\hline \multirow{2}{*}{ Local de coleta } & \multicolumn{7}{c}{ Parâmetros } \\
\cline { 2 - 7 } & fêmeas coletadas & Tamanho* & Peso & $\begin{array}{c}\text { fêmeas observadas em } \\
\text { Cuidado Parental }\end{array}$ & desovas observadas & cardumes observados \\
\hline EET & 35 & $42,33 \pm 2,54$ & $8,75 \pm 2,37$ & 28 & 8 & 20 \\
RECD & 30 & $41,18 \pm 4,44$ & $5,54 \pm 2,12$ & 11 & 4 & 7 \\
Total & 65 & - & - & 39 & 12 & 27 \\
\hline
\end{tabular}


Tabela II. Parâmetros da distância (metros) entre fêmeas de Leptodactylus natalensis e sua prole, de acordo com os diferentes estágios de desenvolvimento larval (segundo Gosner, 1960). (* Não foram observadas fêmeas em cuidado parental).

\begin{tabular}{lcccc}
\hline \multirow{2}{*}{ Parâmetros } & \multicolumn{4}{c}{ Estágios de desenvolvimento larval } \\
\cline { 2 - 5 } & Ninho & Inicial & Intermediário & Final \\
\hline Amplitude & $0-0,2$ & $0-0,5$ & $0-1,5$ & $*$ \\
Média & 0,016 & 0,24 & 0,29 & $*$ \\
Desvio padrão & 0,052 & 0,13 & 0,29 & $*$ \\
$\mathrm{~N}$ & 5 & 5 & 5 & 3 \\
\hline
\end{tabular}

\section{DISCUSSÃO}

Em anuros, a forma mais comum de cuidado parental é a atenção dispensada aos ovos, que são mantidos em condições ideais de umidade, protegidos contra adversidade ambiental e predadores. Na verdade a permanência da fêmea junto à desova e em bacias cobertas por folhedo pode reduzir a vulnerabilidade à predação; espécie que assiste ovos em um local com ninho subterrâneo ou arbóreo e não parte para forragear pode ser menos exposta a predador (CRUMP, 1996). A segunda forma de cuidado parental é a assistência às larvas, que pode durar até o final do desenvolvimento larval (WeLLS, 1981; Duellman \& Trueb, 1986; Martins, 2001). Durante este trabalho, entretanto, a assistência às larvas restringiu-se aos estágios iniciais e intermediários de desenvolvimento (Tab. II). O registro de machos de $L$. natalensis construindo bacias pode representar uma especialização evolutiva paternal, podendo ser caracterizado como um investimento parental (WeLLS \& BARD, 1988; Downie, 1996; MarTins, 2001).

Nas espécies de anfíbios, onde ocorre o cuidado parental, de um modo geral, a principal função dos pais é defender sua prole contra predadores. Nessas espécies, o cuidado parental pode se apresentar sob diferentes estratégias comportamentais, como exibições agonísticas, camuflagem e deslocamentos da prole para locais mais "seguros" (VAZ-FerReIRA \& GeHRAU, 1975; Wells \& BARD, 1988). Wells \& BARD (1988) ressaltam que a defesa exibida durante as interações entre indivíduo, tais como confrontos corporais e vocais, parece ser uma estratégia mais eficiente para anuros de grande porte contra predadores de tamanho equivalente. No entanto, esta estratégia não seria tão vantajosa para espécies pequenas, como é o caso da espécie estudada no presente trabalho, que podem apresentar outros tipos de defesa (Martins, 2001; Prado et al., 2002). Em L. ocellatus Linnaeus, 1758 foi observado fêmea atacando pequenos pássaros que predavam seus girinos (VAZFerreira \& Gehrau, 1975). Wells \& Bard (1988) registraram fêmeas de L. bolivianus Boulenger, 1758, investindo contra objetos estranhos colocados próximo à sua prole. Espécies semelhantes em tamanho a $L$. ocellatus e L. bolivianus, que possuem comprimento rostro-anal (CRA) de 9 e $11 \mathrm{~cm}$, respectivamente (PRADO et al., 2000), têm a vantagem de poder intimidar pequenos vertebrados. Espécies menores, como L. validus Garman, 1888 e L. podicipinus Cope, 1862 (CRA = 4,5 e 3,5 cm, respectivamente) apresentam no seu repertório de defesa outras estratégias, como exibições agonísticas de arquear o corpo, vocalizar e deslocar-se para locais mais seguros. MarTins (2001) registrou fêmeas de L. podicipinus com cardumes escondidos entre a vegetação, predando pequenos invertebrados predadores de larvas, ao mesmo tempo em que deslocava as larvas para outros pontos do ambiente aquático. Comportamento similar foi registrado para $L$. natalensis; as fêmeas foram observadas entre a vegetação, geralmente durante o dia, predando aranhas que se aproximavam do ninho ou do cardume, bem como outros insetos (náiades de libélulas e alguns hemípteros), promovendo o deslocamento do cardume para outros pontos da poça.

O comportamento de fêmeas em assistência à prole já foi relatado para algumas espécies de Leptodactylidae (Vaz-Ferreira \& Gehrau, 1975; Wells \& Bard, 1988), tanto para os ovos em ninho de espuma, quanto para as larvas (Downie, 1996; Martins, 2001). Martins (2001) observou fêmeas, com larvas entre os estágios 44 a 45 (GosNER, 1960), distantes da prole, sugerindo um cessar de interferência química sobre a prole. Em nosso estudo não registramos fêmeas em cuidado parental com girinos entre os estágios 41 a 46; é possível que abandonem o cardume nesta fase ou tenham sido predadas, fato que possivelmente corrobora a sugestão de MARTINS (2001).

O comportamento de bombeamento só havia sido citado, até então, para L. bolivianus (Wells \& BARD, 1988), L. validus (Downie, 1996) e L. podicipinus (Martins, 2001). O registro desse comportamento, efetuado durante este estudo para L. natalensis, sugere um padrão comportamental estereotipado que pode estar relacionado com a filogenia deste grupo. Nossos dados estão de acordo com aqueles obtidos por DowNIE (1996) e Martins (2001), que sugerem que este tipo de comportamento permite a comunicação e a interação entre a fêmea e o cardume, através de um sinal mecânico. A possível ocorrência de comunicação química citada por Martins (2001) não pode ser descartada e exige uma investigação mais aprofundada.

O gênero Leptodactylus compreende cinco grupos: ocellatus, fuscus, melanonotus, pentadactylus e marmoratus (HEYER, 1969). Leptodactylus natalensis pertence ao grupo melanonotus (complexo podicipinus/ wagneri HeYer, 1994). Os dados aqui apresentados vêm reforçar a hipótese de HEYER (1969) de que as espécies dos grupos melanonotus (e.g. L. validus e L. podicipinus) e ocellatus (e.g. L. bolivianus e L. ocellatus) são mais aparentadas entre si do que com os outros grupos.

PRADO et al. (2000) e MARTins (2001) não observaram nos seus estudos a construção de túneis e nem a emissão de sons por fêmeas de L. podicipinus, que é a espécie mais aparentada a L. natalensis, segundo Heyer (1994). Neste estudo, foram acrescidas ao repertório comportamental mais duas estratégias de cuidado parental para as espécies do grupo melanonotus, especialmente para L. natalensis: construção de túneis e a vocalização em fêmeas. A construção de canaletas é conhecida para a rã-touro-africana (Pyxicephalus adspersus Tschudi, 1838), que protege suas larvas até a metamorfose e chega a construir canais que ajudam a livrar girinos, que estão em poças rasas, da ação de 
predadores e da morte por dessecação (DuEllman \& TRUEB, 1986). É importante ressaltar a necessidade de mais investigações sobre estes eventos, para conhecimento dos seus custos e benefícios, bem como para acompanhar a evolução do cuidado parental para as espécies do gênero Leptodactylus.

Agradecimentos. Às biólogas Magnólia da Conceição Botelho e Luciana Cristina da S. Santos pela ajuda no campo; às professoras Maria Adélia B. Oliveira (Universidade Federal Rural de Pernambuco), Eliza Maria X. Freire e Fabíola da Silva Albuquerque (Universidade Federal do Rio Grande do Norte), pela leitura e sugestões ao manuscrito; aos coordenadores e funcionários da Estação Ecológica do Tapacurá e do Refúgio Ecológico Charles Darwin pelo auxílio prestado; a CAPES pela bolsa concedida.

\section{REFERÊNCIAS BIBLIOGRÁFICAS}

BiCKFoRD, D. P. 2004. Differencial parental care behaviors of arboreal and terrestrial microhilid frogs from Papua New Guinea. Behavior Ecology Sociobiology 55:402-409.

Crump, M. L. 1996. Parental care among the amphibia. In: Rosenblan, J. S. \& SNowdon, C. T. eds. Advances in the study of behavior. New York, Academic Press. v.25, p.109-144.

DownIE, J. R. 1996. A new example of female parental behaviour in Leptodactylus validus, a frog of the leptodactylid "melanonotus" species group. Herpetological Journal 6:32-34.

Duellman, W. E. \& Trueb, L. 1986. Biology of Amphibians. New York, McGray-Hill. 670p.

EMLEN, S. T. 1968. A technique for marking anuran amphibians for behavioral studies. Herpetology 24(2):172-173.

Gallardo, J. M. 1964. Considerações sobre Leptodactyulus ocellatus (Amphybia, Anura) y especies aliadas. Physis 24:373-384.

GosNer, K. L. 1960. A simplified table for staging anuran embryos and larvae notes on indentification. Herpetologica 43:467-481.

HeYer, R. 1969. The adaptive ecology of the species groups of the genus Leptodactylus (Amphibia, Leptodactylidae). Evolution 23:421-428.

1994. Variation within the Leptodactylus podicipinis- wagneri complex of frog (Amphibia, Leptodactylidae). Smithsonian Contributions to Zoology 546:1-124.

Heyer, R. \& Carvalho, C. M. 2000. Calls and calling behavior of the frog Leptodactylus natalensis (Amphibia, Anura, Leptodactylidae). Proceeding of the Biological Society of Washington 113(1):284-290.

Martin, P. \& Bateson, P. 1986. Measuring Behaviour. An introductory guide. Cambridge, Cambridge University. 200p.

Martins, I. A. 2001. Parental care behaviour in Leptodactyulus podicipinus (Cope, 1982) (Anura, Leptodactylidae). Herpetological Journal 11:29-32.

Martins, M.; Pombal, J. P., JR. \& Haddad, C. F. B. 1998. Escalated aggressive behaviour and facultative parental care in the nest building gladiador frog, Hyla faber. Amphibia-Reptilia 19:65-73.

MartoF, B. S. 1953. Territoriality in the green frog Rana clamitans. Ecology 34:165-174.

Oliveira, F. F. \& Lírio-JR., G. P. L. 2000. Anfíbios anuros do Campus da Universidade Federal de Sergipe. Biologia Geral Experimental 1(1):42-74.

Prado, C. P. A.; Uetanabaro, M. \& Haddad, C. F. B. 2002. Description of a new reproductive mode in Leptodactylus (Anura, Leptodactylidae), with a review of the reproductive specialization toward terrestriality in the genus. Copeia 4:1128-1133.

Prado, C. P. A.; Uetanabaro, M. \& Lopes, F. S. 2000. Reproductive strategies of Leptodactylus chaquensis and $L$. podicipinus in the Pantanal, Brazil. Journal of Herpetology 34:135-139.

Trivers, R. L. 1972. Parental investiment and sexual selection. In: Campbell, B. G. ed. Sexual Selections and the Descent of man. Chicago, Aldine. p.136-179.

Vaz-Ferreira, R. \& Gehrau, A. 1975. Epimeletic behaviour of the common frog, Leptodactylus ocellatus (L.) (Amphibia, Leptodactylidae). I. Attention to the todpole and related feeding and agressive activities. Physis 34:1-14.

Wells, K. D. 1981. Parental behavior of male and female frogs. In: Alexander, R. D. \& Tinkle, D. W. eds. Natural Selection and Social Behavior: Recent Research and New Theory. New York, Chiron Press. p.184-197.

Wells, K. D. \& BARD, K. M. 1988. Parental behavior of an aquatic-breeding tropical frog, Leptodactylus bolivianus. Journal of Herpetology 22:361-364.

Recebido em novembro de 2004. Aceito em agosto de 2006. ISSN 0073-4721

Artigo disponível em: www.scielo.br/isz 